\title{
Gambaran Sistem Pengelolaan Rekam Medis di RSUD Dr. Soehadi Prijonegoro
}

\section{The Medical Record Management System in Dr. Soehadi Prijonegoro Hospital}

\author{
Prita Devy Igiany ${ }^{1}$, Husnun Afifah ${ }^{2}$, Vina Istiqomah ${ }^{3}$ \\ Program Rekam Medis dan Informasi Kesehatan, Universitas Veteran Bangun Nusantara ${ }^{1,2,3}$ \\ Email : pritadevyigiany90@gmail.com
}

\begin{abstract}
The administration of medical records is a factor that determines and reflects the good or bad health of health services. The achievement of the objectives of medical records is related to how medical records are organized. Medical records are very important in health services. This is because medical records not only provide legal information, but also become one of the important things in assessing the quality of service. Medical record service is one of the medical supports services in a hospital which is the basis for assessing the quality of hospital medical services. This research was conducted using a descriptive study. The purpose of this descriptive study was to describe the medical record document management system in dr.Soehadi Prijonegoro Sragen Hospital. This type of research is a descriptive survey. Data collection was carried out in July 2019. Primary data was obtained by direct observation of the process of implementing medical records, interviews, and observing medical record files to see the completeness of medical records. Secondary data were obtained from a review of documents at dr.Soehadi Prijonegoro Sragen Hospital. The results of this study include, 1) a naming system based on KTP; 2) numbering using the UNS system; 3) alignment using the TDF system; 4) centralized storage; 5) processing system consisting of assembling, coding, indexing, filing, reporting; 6) Destruction is carried out every 4 years.
\end{abstract}

Keywords: hospital, medical record, system

\begin{abstract}
ABSTRAK
Penyelenggaraan rekam medis merupakan faktor yang menentukan dan mencerminkan baik atau buruknya pelayanan kesehatan. Tercapainya tujuan penyelenggaraan rekam medis berhubungan dengan bagaimana rekam medis tersebut diselenggarakan. Rekam medis merupakan hal yang sangat penting dalam pelayanan kesehatan. Hal ini jarena rekam medis tidak hanya menyediakan informasi legal, namun juga menjadi salah satu hal yang penting dalam menilai mutu pelayanan. Pelayanan rekam medis merupakan salah satu pelayanan penunjang medis di rumah sakit yang menjadi dasar penilaian mutu pelayanan medik rumah sakit. Penelitian ini dilakukan dengan menggunakan studi deskriptif. Tujuan dari penelitian deskriptif adalah menggambarkan sistem pengelolaan dokumen rekam medis di RSUD dr.Soehadi Prijonegoro Sragen. Jenis penelitian adalah survei yang bersifat deskriptif. Pengambilan data dilakukan bulan Juli 2019. Data primer diperoleh dengan cara pengamatan langsung terhadap proses pelaksanaan rekam medis, wawancara, serta observasi berkas rekam medis untuk melihat kelengkapan rekam medis. Data sekunder diperoleh dari telaah dokumen yang ada di RSUD dr.Soehadi Prijonegoro Sragen. Adapun hasil dari penelitian ini antara lain, 1) sistem penamaan berdasarkan KTP; 2) sistem penomoran menggunakan sistem UNS; 3) sistem penjajaran menggunakan sistem TDF; 4) sistem penyimpanan secara sentralisasi; 5) sistem pengolahan terdiri dari assembling, coding, indexing, filing, pelaporan; 6) pemusnahan dilakukan setiap 4 tahun.
\end{abstract}

Kata kunci: rumah sakit, rekam medis, sistem 


\section{PENDAHULUAN}

Menurut SK Menteri Kesehatan RI No. 983 Tahun 1992, tugas rumah sakit adalah melaksanakan upaya kesehatan berdaya guna dan berhasil guna, serasi dan terpadu dengan upaya peningkatan dan pencegahan serta melaksanakan upaya rujukan. Fungsi rumah sakit itu sendiri adalah tempat menyelenggarakan pelayanan medik, pelayanan penunjang, pelayanan keperawatan, pelayanan rehabilitasi, dan pelayanan pencegahan penyakit. Dengan demikian rumah sakit merupakan institusi yang multi produk, padat modal, padat karya, dan padat teknologi, sehingga memerlukan manajemen yang baik dalam pengelolaannya (Hatta, 2011). Salah satu unsur utama dalam sistem pelayanan kesehatan yang prima adalah tersedianya pelayanan medis oleh dokter dan dokter gigi dengan kualitasnya yang terpelihara sesuai dengan amanah Undang-Undang Nomor 29 Tahun 2004 tentang Praktik Kedokteran. Dalam penyelenggaraan praktik kedokteran, setiap dokter dan dokter gigi wajib mengacu pada standar, pedoman dan prosedur yang berlaku sehingga masyarakat mendapat pelayanan medis secara profesional dan aman. Sebagai salah satu fungsi pengaturan dalam UU Praktik Kedokteran yang dimaksud adalah pengaturan tentang rekam medis yaitu pada Pasal 46 dan Pasal 47 (Konsil Kedokteran Indonesia, 2006).

PERMENKES No:269/MENKES/PER/ III/2008 menjelaskan bahwa yang dimaksud rekam medis adalah berkas yang berisi catatan dan dokumen antara lain identitas pasien, hasil pemeriksaan, pengobatan yang telah diberikan, serta tindakan dan pelayanan lain yang telah diberikan kepada pasien (PERMENKES No. 269 Tahun 2008). Pengertian singkat rekam medis hanya merupakan catatan dan dokumen tentang keadaan pasien. Akan tetapi lebih jauh lagi rekam medis mempunyai makna lebih dari pada hanya catatan biasa karena dalam catatan tersebut sudah tercermin segala informasi didalamnya menemukan tindakan lebih lanjut dalam upaya pelayanan maupun tindakan medis lainnya, yang diberikan kepada seorang pasien yang datang ke pelayanan kesehatan (Ritonga \& Rusanti, 2018).

Dalam penyelenggaraan pelayanan kesehatan Rumah Sakit, penyelenggaraan rekam medis merupakan faktor yang menentukan dan mencerminkan baik atau buruknya pelayanan tersebut. Rekam medis sangat mendukung bukan hanya untuk menyelenggarakan proses instrumen yang penting dalam menangani masalah mediko-legal yang mungkin terjadi di rumah sakit kurang berhasil dalam upaya meningkatkan mutu pelayanan sebagaimana yang di harapkan (RSUD H. Abdul Aziz Marabahan, 2019). Pelayanan rekam medis merupakan salah satu pelayanan penunjang medis di rumah sakit yang menjadi dasar penilaian mutu pelayanan medik rumah sakit. Rekam medis pasien berisi informasi tentang catatan dan dokumen tentang identitas pasien, pemeriksaan, pengobatan, tindakan dan pelayanan lain yang telah diberikan kepada pasien (Departemen Kesehatan RI, 2006). Tercapainya tujuan penyelenggaraan rekam medis berhubungan dengan bagaimana rekam medis tersebut diselenggarakan (Utami, 2011).

Penelitian yang dilakukan oleh Ritonga \& Susanti (2018) mengenai proses pengelolaan rekam medis di Rumah Sakit Umum Bunda Thamrin menunjukkan ada beberapa hal yang tidak sesuai antara lain jumlah tenaga yang masih kurang dan terutama yang latar belakang pendidikannya rekam medis, fasilitas ruangan yang kecil dan sempit, ruangan penyimpanan yang jauh dari tempat penerimaan pasien, jumlah rak penyimpanan berkas rekam medis yang kurang dan pengisian formulir yang belum lengkap. Kesesuaian pengelolaan rekam medis dengan standar akan menambah mutu dari pelayanan rumah sakit. RSUD dr. Soehadi Prijonegoro Kab. Sragen (dahulu RSUD Sragen) merupakan Rumah Sakit Negeri yang berlokasi di Kabupaten Sragen, Jawa Tengah. Hingga kini RSUD dr.Soehadi Prijonegoro Sragen menjadi rumah sakit pilihan dan telah memiliki 
pasien dari berbagai daerah di sekitar Kabupaten Sragen seperti Kabupaten Ngawi, Jawa Timur, Grobogan, Karanganyar dan masyarakat Sragen sendiri pada umumnya. RSUD dr. Soehadi Prijonegoro Sragen selain memberikan pelayanan pasien secara individu melayani pasien karyawan perusahaan dan klien perusahaan asuransi. Berdasarkan uraian tersebut, maka peneliti tertarik untuk mengetahui bagaimana gambaran sistem pengelolaan rekam medis di RSUD dr.Soehadi Prijonegoro Sragen.

\section{METODE}

Penelitian ini adalah penelitian kualitatif yang bersifat deskriptif. Sumber data yang digunakan dalam penelitian ini adalah data primer dan data sekunder. Data primer yaitu data yang diperoleh dari beberapa informan dan informan kunci melalui wawancara mendalam. Peneliti akan menggunakan pedoman wawancara dan melakukan pendokumentasian dengan menggunakan recorder. Data sekunder yaitu data yang diperoleh dari dokumen dan literatur seperti pedoman pelayanan rekam medis RSUD dr.Soehadi Prijonegoro Sragen. Metode pengumpulan data dengan melakukan wawancara dan pengamatan (Observation) selama Bulan Juli 2019. Keabsahan data diperiksa dengan melakukan triangulasi data, dalam penelitian ini, keabsahan data dilakukan dengan triangulasi metode, yaitu wawancara, observasi dan studi literatur. Teknik pengolahan dan analisis data dilakukan dengan reduksi data, penyajian data, kesimpulan dan verifikasi (Notoatmodjo, 2012).

\section{HASIL DAN PEMBAHASAN}

\section{Sistem Penerimaan Pasien}

\section{a. Penerimaan Pasien Rawat Jalan (TPPRJ)}

Setiap pasien baru akan memperoleh nomor pasien yang dicetak pada kartu pasien yang harus dibawa pada setiap kunjungan berikutnya di RSUD dr. Soehadi Prijonegoro Sragen baik sebagai pasien berobat jalan maupun sebagai pasien rawat inap. Untuk pasien yang harus di rawat, dokter yang merujuk membuat rujukan berisi alasan pasien harus dirawat inap, bisa berupa diagnosa, tindakan medis, ataupun tindakan penunjang lainnya. Jika pasien yang harus dirawat maka keluarga pasien mengurus proses pendaftaran rawat inap dan rekam medisnya akan dikirim keruang perawatan.

Sedangkan pelayanan bagi pasien lama, akan langsung dibedakan berdasar jenis pembayaran yang dipilih dan diminta melengkapi syarat-sarat untuk klaim penanggung biaya perawatannya, lalu pasien diarahkan menuju klinik yang dituju sementara dokumen rekam medisnya akan disisipkan oleh petugas. Setelah rekam medisnya dikirim ke klinik, pasien akan mendapat pelayanan di klinik dimaksud. Berbeda dengan prosedur pelayanan pasien baru dan pasien lama yang biasa, pasien gawat darurat akan ditolong terlebih dahulu baru penyelesaian administrasinya, meliputi pendaftaran pasien baik baru maupun ulang. Di RSUD dr. Soehadi Prijonegoro Sragen pendaftaran pasien darurat dilakukan di TPPRI untuk pasien baru maupun pasien lama.

\section{b. Penerimaan Pasien Rawat Inap (TPPRI)}

Penerimaan pasien rawat inap dilakukan di TPPRI di RSUD dr. Soehadi Prijonegoro Sragen dibagi menjadi 3 kelompok yaitu pasien yang urgen, penundaan perawatan pasien tersebut tidak akan menambah penyakitnya, pasien yang urgen, tetapi tidak darurat gawat, dapat dimasukkan ke dalam daftar tunggu dan pasien gawat darurat (emergency), langsung dirawat. 


\section{Sistem Identifikasi}

\section{a. Sistem Penamaan}

Sistem Penamaan pada dasarnya untuk memberikan identitas kepada seorang pasien serta untuk membedakan antara pasien satu dengan yang lainnya, sehingga mempermudah atau memperlancar didalam memberikan pelayanan rekam medis (Departemen Kesehatan RI, 2008; Judi, 2017). Di RSUD dr. Soehadi Prijonegoro Sragen, sistem yang digunakan adalah sistem penamaan langsung yaitu yang ditulis dalam database adalah nama pasien sendiri berdasarkan kartu tanda pengenal dan dapat ditambahkan sesuai dengan wawancara terakhir. Prinsip utama yang harus ditaati oleh petugas pencatat adalah nama pasien harus lengkap, apabila nama pasien lebih dari dua suku kata, penulisan minimal terdiri dari dua suku kata. Berdasarkan hasil penelitian, prinsip-prinsip tersebut sudah di lakukan dan di taati oleh petugas.

\section{b. Sistem Penomoran}

Menurut Depkes RI (2008) sistem pemberian nomor pasien masuk (Admission Numbering System) yang umum dipakai yaitu: Pemberian nomor cara seri (Serial Numbering System) (Departemen Kesehatan RI, 2008). Sistem penomoran di RSUD dr. Soehadi Prijonegoro Sragen menggunakan Unit Number System (UNS), yaitu sistem yang memberikan satu unit rekam medis baik kepada pasien berobat rawat jalan maupun rawat inap, diberikan satu nomor yang akan dipakai selamanya untuk kunjungan seterusnya. Masalah yang biasa timbul dengan penggunaan UNS adalah jika pasien sering berkungjung dan mendapat pengobatan, maka rekam medisnya akan menjadi berjilid-jilid. Untuk mengatasi permasalahan tersebut petugas membuat jilid baru dan disetiap jilid harus dibuat catatan nomor jilid dan jumlah jilidnya, misalnya : jilid 1 dari 2; jilid 2 dari 2. Untuk sumber nomor RSUD dr. Soehadi Prijonegoro Sragen membuat satu "bank nomor" terdiri dari 6 angka. Bank nomor dikeluarkan oleh bagian TPPRJ yang dibuat secara manual.

\section{c. Sistem Penjajaran}

Sistem Penjajaran yang digunakan RSUD dr. Soehadi Prijonegoro Sragen adalah (Terminal Digit Filling) TDF dan menggunakan satu digit saja. Keuntungan dari sistem satu digit adalah petugas hanya memperhatikan pada satu angka terakhir. Sedangkan kerugian dari sistem ini, menggunakan satu digit ini adalah lebih lama dalam pengambilan dokumen pasien daripada dengan memperhatikan dengan dua angka akhir (Shofari, 2004).

\section{d. Sistem Penyimpanan}

Sistem penyimpanan sentralisasi merupakan penyimpanan rekam medis seorang pasien dalam satu kesatuan baik catatan-catatan kunjungan poliklinik maupun catatancatatan selama seorang pasien dirawat dalam satu ruangan yang sama (Judi, 2017). Sistem penyimpanan yang digunakan di RSUD dr. Soehadi Prijonegoro Sragen adalah sistem sentralisasi yang mulai diterapkan pada Bulan Maret tahun 2016 setelah sebelumnya menggunakan sistem desentralisasi. Di gunakannya sistem sentralisasi ini sangat bermanfaat bagi rumah sakit salah satunya menghemat waktu pencarian dokumen dan ruangan yang di pergunakan untuk menyimpan dokumen rekam medis (RSUD H. Abdul Aziz Marabahan, 2019). 


\section{Sistem Pengolahan}

\section{a. Assembling (Perakitan)}

Menurut Budi (2011) seharusnya kegiatan assembling termasuk juga mengecek kelengkapan pengisian berkas rekam medis dan formulir yang harus ada pada berkas rekam medis (Budi, 2011). Assembling di RSUD dr. Soehadi Prijonegoro Sragen hanya merakit dokumen rekam medis, agar dokumen rekam medis dapat dibaca secara kronologis dan memberikan informasi medis secara jelas. Assembling di RSUD dr. Soehadi Prijonegoro Sragen terbagi menjadi dua yaitu, assembling rawat jalan dan assembling rawat darurat atau rawat inap.

\section{b. Coding (Pengkodean)}

Koding adalah kegiatan memberikan kode diagnosis dan kode tindakan medis menurut World Health Organization (WHO). Kegiatan dan tindakan, serta diagnosis yang ada di dalam rekam medis harus diberi kode untuk menunjang fungsi perencanaan, manajemen, dan riset kesehatan (Departemen Kesehatan RI, 2006). Pengkodean yang digunakan RSUD dr. Soehadi Prijonegoro Sragen menggunakan ICD 10 untuk kode diagnosis, sedangkan untuk kode tindakan menggunakan ICD 9 CM secara elektronik menurut WHO. Kode klasifikasi penyakit oleh WHO bertujuan untuk menyeragamkan nama dan golongan penyakit, cidera, gejala, dan faktor yang mempengaruhi kesehatan.

\section{c. Indexing}

Indeks pasien berisi data semua pasien yang pernah berobat di RSUD dr. Soehadi Prijonegoro Sragen. Informasi yang ada di dalam data base ini adalah: nama lengkap, jenis kelamin, umur, alamat, tempat dan tanggal lahir, tanggal berobat jalan maupun rawat inap. Database tersusun secara alphabet seperti susunan kata-kata dalam kamus. Database ini digunakan untuk mencari dokumen rekam medis pasien yang tidak membawa kartu berobat sehingga dapat dicari berdasarkan nama pasien. Database dikontrol setiap hari oleh petugas di Instalasi Perekam Medis dan Informasi Kesehatan sehingga data selalu up to date.

Indeks penyakit dan operasi di RSUD dr. Soehadi Prijonego Sragen berisi nomor kode diagnosa penyakit atau tindakan operasi, tanggal, bulan, tahun serta nomor RM pasien. Indeks penyakit dan operasi akan di back up secara rutin untuk mencegah kehilangan atau kerusakan data. Indeks kode diagnosis dan tindakan di RSUD dr. Soehadi Prijonegoro Sragen dibagi menjadi dua yaitu rawat jalan dan rawat inap atau rawat darurat. Indeks rawat jalan di indeks melalui aplikasi SIMRS dan indeks rawat inap atau gawat darurat di indeks melalui aplikasi SIMPATI. Indeks Dokter, berisi nama dokter yang memberikan pelayanan medik kepada pasien yang digunakan untuk menilai pekerjaan dokter dan sebagai bank data dokter bagi RSUD dr. Soehadi Prijonegoro Sragen. Selain itu, terdapat juga indeks kematian, yang berisi informasi nama pasien, nomor RM, jenis kelamin, umur, kode diagnosis, sebab kematian, dokter yang merawat, lama dirawat.

\section{d. Filling}

Dalam unit rekam medis di RSUD dr. Soehadi Prijonegoro Sragen, bagian filling mempunyai kewajiban menyimpan dokumen rekam medis dan menjaga kerahasiaan lainnya. Untuk dokumen yang sudah lengkap akan di assembling, koding dan di indeks lalu dimasukkan ke dalam folder dan ditulis nama lengkap pasien beserta nomor RM-nya, baik dari rawat inap maupun dari rawat jalan. Kemudian dokumen tersebut diurutkan sesuai dengan angka akhir nomor rekam medis tersebut antara dua nomor akhir rekam 
medis yang genap dan ganjil, lalu dokumen tersebut di simpan di rak ruang filling. Jika di temukan kesamaan nama dan nomor RM, dokumen tersebut disatukan.

Dalam pelaksanaan penyimpanan berkas rekam medis diperlukan adanya fasilitas yang memadai bagi berkas rekam medis itu sendiri maupun bagi petugas pelaksana penyimpanan berkas rekam medis. Pemilihan rak penyimpanan harus dilakukan dengan turut mempertimbangkan lokasi penyimpanan, sistem penomoran rekam medis, lama simpan rekam medis dan tipe serta harga peralatan penyimpanan sedangkan untuk peralatan antara rak satu dengan rak lainnya, perlu adanya jarak untuk memudahkan para petugas dalam menjalankan tugasnya (Hatta, 2008)

\section{e. Pelaporan}

Pelaporan di RSUD dr. Soehadi Prijonegoro Sragen dilakuukan dengan mengumpulkan, mengolah dan melakukan analisis terhadap kinerja rumah sakit. Jenis laporan yang di susun berupa laporan harian, bulanan, tahunan maupun insidental.

\section{f. Pemusnahan Rekam Medis}

Dokumen rekam medis di RSUD dr. Soehadi Prijonegoro Sragen yang sudah dinyatakan in-aktif di hitung semenjak pasien terakhir pulang dari rawat inap maupun terakhir berkunjung ke rumah sakit selama 4 tahun terakhir. Setelah 4 tahun berlalu dokumen rekam medis di lakukan penyusutan lalu di musnahkan kecuali dokumen yang di abadikan. Dokumen yang di abadikan akan di simpan selama kurun waktu 10 tahun terhitung dari tanggal di buatnya ringkasan tersebut. Di RSUD dr. Soehadi Prijonegoro Sragen pemusnahan dokumen rekam medis belum sesuai dengan PERMENKES No. 269 pasal 8 ayat 1 dan 2 yaitu 5 tahun sedangkan di RSUD dr. Soehadi Prijonegoro Sragen pemusnahan rekam medis dilakukan selama 4 tahun dihitung sejak pasien terakhir berkunjung ke rumah sakit di karenakan kurangnya lahan penyimpanan untuk dokumen rekam medis.

\section{KESIMPULAN}

Adapun kesimpulan dari penelitian ini antara lain, 1) sistem penamaan berdasarkan KTP; 2) sistem penomoran menggunakan sistem UNS; 3) sistem penjajaran menggunakan sistem TDF; 4) penyimpanan dilakukan secara sentralisasi; 5) sistem pengolahan terdiri dari assembling, coding, indexing, filing, pelaporan; 6) pemusnahan berkas rekam medis dilakukan setiap 4 tahun.

\section{SARAN}

Peneliti menyarankan, hasil penelitian ini untuk dapat dijadikan acuan perbaikan sistem penyelenggaraan rekam medis di RSUD dr. Soehadi Prijonegoro Sragen terutama dalam pemusnahan berkas rekam medis. Selain itu peneliti juga menyarankan agar dapat dilakukan penelitian selanjutnya, untuk mengkaji lebih jauh faktor-faktor yang dapat mempengaruhi proses penyelenggaraan rekam medis di RSUD dr. Soehadi Prijonegoro Sragen.

\section{DAFTAR PUSTAKA}

Budi, S. (2011). Unit Kerja Rekam Medis. Yogyakarta: Quantum Sinergis Media.

Departemen Kesehatan RI. (2006). Pedoman Penyelenggaraan dan Prosedur Rekam Medis Rumah Sakit di Indonesia Revisi II. Jakarta: Direktorat Jenderal Bina Pelayanan Medik. 
Departemen Kesehatan RI. (2008). Petunjuk Pelaksanaan Penyelenggaraan Rekam Medis. Jakarta.

Hatta, G. (2008). Pedoman Manajemen Informasi Kesehatan di Pelayanan Kesehatan Edisi Revisi. Jakarta: Universitas Indonesia.

Hatta, G. (2011). Pedoman Manajemen Informasi Kesehatan di Sarana Pelayanan Kesehatan. Jakarta: UI PRESS.

Judi. (2017). Tata Kelola Rekam Medis sebagai Upaya Menjaga Rahasia Medis di Pelayanan Kesehatan. Jurnal Manajemen Informasi Kesehatan Indonesia Vol. 5 No. 1, 96-102.

Konsil Kedokteran Indonesia. (2006). Manual Rekam Medis. Jakarta.

Notoatmodjo, S. (2012). Metode Penelitian Kesehatan. Jakarta: Rineka Cipta.

PERMENKES No. 269 Tahun 2008. (n.d.).

Ritonga, Z. A., \& Rusanti, S. (2018). Gambaran Sistem Penyelenggaraan Rekam Medis di Rumah Sakit Umum Buna Thamrin Tahun 2018. Jurnal Ilmiah Perekam dan Informasi Kesehatan Imelda, 498-509.

RSUD H. Abdul Aziz Marabahan. (2019). Pedoman Penyelenggaraan Rekam Medis 2019 RSUD H. Abdul Aziz Marabahan. Marabahan.

Shofari, B. (2004). Pengelolaan Sistem Rekam Medis. Semarang: PORMIKI.

Utami, A. R. (2011). Gambaran Sistem Penyelenggaraan Rekam Medis di RSU Dr. F. L.TOBING SIBOLGA. Medan: Universitas Sumatra Utara. 